\title{
1 Global warming affects nutrient upwelling in deep lakes
}

2 Robert Schwefel ${ }^{1{ }^{1 *}}$, Beat Müller ${ }^{2}$, Hélène Boisgontier ${ }^{1}$, and Alfred Wüest ${ }^{1,2}$

$3 \quad{ }^{1}$ Physics of Aquatic Systems Laboratory, Margaretha Kamprad Chair, École Polytechnique

4 Fédérale de Lausanne (EPFL), Institute of Environmental Engineering, Lausanne, Switzerland.

$5 \quad{ }^{2}$ Eawag, Swiss Federal Institute of Aquatic Science and Technology, Surface Waters - Research 6 and Management, Kastanienbaum, Switzerland.

$7 \quad *$ corresponding author

$8{ }^{\ddagger}$ Current address: UC Santa Barbara, 3015 Marine Science Building, Santa Barbara, CA 93106-

96150 United States; Phone: +1 805 8952157; E-mail: robertschwefel@ ucsb.edu

11 ORCID:

12 Robert Schwefel: 0000-0003-1610-4181; Beat Müller: 0000-0003-3696-9035; Hélène

13 Boisgontier: n/a; Alfred Wüest: 0000-0001-7984-0368

\section{ABSTRACT}

16 Measures to reduce lake phosphorus concentrations have been encouragingly successful in many 17 parts of the world. After significant eutrophication in the $20^{\text {th }}$ century, nutrient concentrations 18 have declined in many natural settings. In addition to these direct anthropogenic impacts, 19 however, climate change is also altering various processes in lakes. Its effects on lacustrine 20 nutrient budget remain poorly understood. Here we investigate the total phosphorus (TP) 21 concentrations in the epilimnion of the meromictic Lake Zug under present and future climatic conditions. Results are compared with those of other deep lakes. Data showed that TP transported from the hypolimnion by convective winter mixing was the most important source of TP for the 24 epilimnion, reaching values more than ten times higher than the external input from the 25 catchment. We found a logarithmic relationship between winter mixing depth (WMD) and 26 epilimnetic TP content in spring. Warming climate affects WMD mainly due to its dependence 27 on autumn stratification. Model simulations predict a reduction of average WMD from $78 \mathrm{~m}$ 28 (current) to $65 \mathrm{~m}$ in 2085 assuming IPCC scenario A2. Other scenarios show similar but smaller 29 changes in the future. In scenario A2, climate change is predicted to reduce epilimnetic TP 30 concentrations by up to $24 \%$ during warm winters and may consequently introduce significant 31 year-to-year variability in primary productivity.

32 Keywords: Limnology, Climate Change, Winter Mixing, Phosphorus, Lake Zug

This document is the accepted manuscript version of the following article: 


\section{INTRODUCTION}

34 Excessive primary productivity fuelled by high nutrient input represents a major concern in many lakes around the world (Vollenweider 1968; Dillon and Rigler 1974; Schindler 2006). Efforts to limit nutrient input from agriculture and urban wastewater led to substantial input reductions in phosphorus $(\mathrm{P})$ and nitrogen concentrations and to reestablishment of oligotrophic nutrient conditions in many formerly eutrophic lakes (De Pinto et al. 1986; Makarewicz 1993; Finger et al. 2013; Müller et al. 2014). However, input reduction has not always resulted in a return to oligotrophic conditions, oxic deepwater, or lower rates of primary production. Overall system response to such drastic changes on relatively short timescales remain unclear. Biomass concentrations (Anneville et al. 2005; Jeppesen et al. 2005) and oxygen depletion rates (Müller et al. 2012a; Schwefel et al. 2018) do not always react in tandem with nutrient concentrations or inputs.

Recent studies have recognized that rising air temperatures also affect lake ecosystems by increasing water temperatures (Schmid et al. 2014; O'Reilly et al. 2015), which in turn affect water column stability as well as nutrient and oxygen budgets of lakes (Sahoo et al. 2013; North et al. 2014; Schwefel et al. 2016; Ficker et al. 2017; Salmaso et al. 2018; Lepori et al. 2018; Rogora et al. 2018). Many studies indicate that climate warming affects eutrophication through increased plankton growth rates, increased internal P loading (North et al. 2014), higher nutrient inputs from the catchments (Moss et al. 2011), or shifts in phytoplankton community structure (Anneville et al. 2002). Few studies, however, have directly queried the relationship between water column structure and hypolimnetic nutrient upwelling into the euphotic zone of lakes during winter mixing. While primary productivity in shallow lakes is mainly controlled by inflows from the catchment, deep lakes have considerable quantities of nutrients stored in the deep hypolimnion. These can increase productivity when penetrative convective events or strong winds allow mixing with the euphotic zone. The deep lakes of the East African rift, Lake Kivu and Lake Tanganyika, are classic examples of settings where deep mixing is the main driver of interannual changes in productivity. Lakes Constance and Garda offer mid-latitude examples of settings, where nutrient availability depends to a substantial degree on winter mixing depth (WMD) (Straile et al. 2003; Salmaso et al. 2018). In oligomictic Lake Lugano, Simona (2003) found that nutrient availability and phytoplankton composition depended on WMD. North et al. (2014) observed no reduction in P transport from the hypolimnion to the epilimnion of Lake 
Zürich, in spite of reduced convective mixing in winter. Yankova et al. (2017) meanwhile reported decreased upwelling of nutrient-rich deep-water in Lake Zürich with potential impacts on primary productivity.

This study interprets long-term monitoring data from the deep, meromictic Lake Zug (Fig. 1) for evidence of diminished deep convective mixing during winter and associated decline in epilimnetic $\mathrm{P}$, which is considered the limiting nutrient as in many lakes worldwide. A detailed dataset spanning 35 years allows for quantitative analysis of the dependency of epilimnetic total phosphorus (TP) concentrations on WMD and in turn variation in WMD with changing meteorological conditions (Fig. 1b). A one-dimensional model provides predictions on mixing behaviour under different IPCC climate scenarios and their impact on Lake Zug's P budget.

The goals of this study were to (1) understand the epilimnetic P budget of Lake Zug and its dependency on WMD, (2) estimate WMD using climate data, (3) evaluate predicted changes in winter deep mixing under conditions of a warming climate, and (4) interpret the impact of WMD on the TP input to the epilimnion. To address these goals, we analysed monthly temperature, salinity, and TP profiles at the deepest location of the lake, along with estimates for external $\mathrm{P}$ load, TP outflow, and P net sedimentation (Müller et al. 2012b). Lake Zug provides an ideal dataset for evaluating the effect of global warming on the $\mathrm{P}$ budget in the productive surface layer of deep lakes.

\section{METHODS}

\section{Background on Lake Zug}

Lake Zug is a meromictic, eutrophic lake resting at $413 \mathrm{~m}$ elevation in central Switzerland. The lake has a surface area of $38.4 \mathrm{~km}^{2}$, a volume of $3.18 \mathrm{~km}^{3}$, a mean depth of $\sim 83 \mathrm{~m}$ and a maximum depth of $198 \mathrm{~m}$ (Fig. 1). Due to low inflow relative to lake volume, the mean water residence time of 14.2 years is long for a lake of this size. Surrounding mountains shield the dominant western winds, hence, wind speeds rarely exceed $2 \mathrm{~m} \mathrm{~s}^{-1}$ (mean wind speed: $1.47 \mathrm{~m} \mathrm{~s}^{-1}$; Fig. S1; Wüest and Gloor 1998). These conditions contribute to a slight salinity gradient and form weak but permanent water column stratification in the hypolimnion. Complete deep mixing during winter occurs only rarely. Since the beginning of continuous monitoring in 1950, Lake Zug has mixed to maximum depth only once, in 2006 when temperatures completely homogenized, and oxygen concentrations increased from anoxic conditions to $\sim 5 \mathrm{mg}^{1^{-1}}$. During 
this particular winter, other deep Swiss lakes such as Lake Geneva or meromictic Lake Lugano also experienced complete mixing (Holzner et al. 2009; Schwefel et al. 2016). As a consequence of the weak mixing, the water column below $\sim 100 \mathrm{~m}$ is anoxic and largely separated from the productive surface layer. Even rare, severe local storm events, referred to as Föhn, do not result in oxygenation of the deep hypolimnion (Imboden et al. 1988).

Nestled in an agricultural region, Lake Zug has a long history of eutrophication caused by urban waste water and agricultural runoff. The trophic history of Lake Zug has been reconstructed using diatom sedimentary records dating back to 1550 (AquaPlus 2001). Historically, Lake Zug was oligotrophic until 1810 when it entered a phase of increasing TP concentrations, which ultimately reached values exceeding $200 \mathrm{mg} \mathrm{m}^{-3}$ during the early 1980s. During this time, Lake Zug was one of the most polluted lakes in Switzerland. Due to improved waste water treatment and reduction of fertilizer use, TP concentrations declined since 1980. However, Lake Zug's volume-weighted average TP concentration remains still at high values of $\sim 80 \mathrm{mg} \mathrm{m}^{-3}$ (Fig. 2). Referring to current $\mathrm{P}$ loads, a recent study predicted TP gradually decreasing to concentrations of $\sim 40 \mathrm{mg} \mathrm{m}^{-3}$ by the end of the $21^{\text {st }}$ century (Müller and Wüest 2016).

\section{Monitoring data}

Since 1950, the Cantonal Office for the Environment has measured temperature, oxygen, conductivity, TP, and several other parameters in profiles collected at the deepest location of the lake (Fig. 1d). Sampling was performed on an approximately monthly basis since 1982 at discrete depths (varying over time but typically between 2.5 to $5 \mathrm{~m}$ resolution in the epilimnion and 10 to $20 \mathrm{~m}$ in the hypolimnion). Oxygen, temperature and conductivity were measured with a multiparameter probe while TP was determined using the molybdenum-blue method after digestion of the unfiltered samples with $\mathrm{K}_{2} \mathrm{~S}_{2} \mathrm{O}_{8}$. TP consists almost entirely of dissolved inorganic phosphorus (Fig. S2), TP concentrations therefore are considered to be representative for the concentrations of bioavailable $\mathrm{P}$. The measured profiles provided estimates of the maximum depth every late winter / early spring convective mixing episode from 1982 to 2016. Oxygen and temperature profiles collected at the end of spring (March to May) define the WMD as the depth at which the temperature gradient becomes negative. This depth typically corresponds to that of the highest local gradient in oxygen concentration. As a proxy for salinity, conductivity profiles provided additional constraints since homogenization of the mixed surface 
layer affects ionic components of the water column as well. Uncertainties in WMD depend on the resolution of the profiles and typically equate to $\pm 10 \mathrm{~m}$.

Since 2005, the Cantonal Office of the Environment has measured fluvial P loads as total dissolved $\mathrm{P}$ (TDP, which is assumed to be the bioavailable fraction) from inflows (representing $\sim 65 \%$ of the catchment area) into Lake Zug. Bioavailability of particulate $\mathrm{P}$ was considered negligible since (mostly soil-derived) particles settle in delta zones of the inflows even though a small fraction of particulate $\mathrm{P}$ may in fact mineralize within the lake to become bioavailable.

Data were then scaled up to the entire lake catchment, assuming proportional TDP concentrations for the remaining $\sim 35 \%$ of the area. The $\mathrm{P}$ export was estimated from the Lorze outflow at Cham (Fig. 1d). Details concerning the P load calculations, export, and net sedimentation can be found in Müller and Wüest (2016) and below.

The Cham weather station $\left(47.188^{\circ} \mathrm{N}, 8.465^{\circ} \mathrm{E}\right)$ situated along Lake Zug's northern shore provided temperature $\left({ }^{\circ} \mathrm{C}\right)$, wind speed $\left(\mathrm{m} \mathrm{s}^{-1}\right)$, wind direction $\left(^{\circ}\right)$, air pressure $(\mathrm{hPa})$, and relative humidity (\%) data (Fig. 1d). The Luzern weather station $\left(47.058^{\circ} \mathrm{N}, 8.300^{\circ} \mathrm{E}\right)$ provided cloud cover (octa) and solar radiation $\left(\mathrm{W} \mathrm{m}^{-2}\right)$ data, which were not available from the Cham station. Cloud cover was not measured in Luzern after 2015 and a data gap exists between 1.1.1998 and 31.3.1998. The Zürich weather station $\left(47.378^{\circ} \mathrm{N}, 8.566^{\circ} \mathrm{E}\right)$ provided data for this period instead. The correlation coefficient between cloud cover in Zürich and that in Luzern was 0.76. The meteorological data were used to determine its correlation with WMD. The one-dimensional lake model SIMSTRAT described below was forced with the meteorological data and provided estimates of lake temperature and water column dynamics under predicted future climatic conditions.

\section{Data analysis}

147 To quantify winter temperatures, measured hourly temperatures from December $1^{\text {st }}$ to March $1^{\text {st }}$ 148 were integrated as temperature-hours $\left({ }^{\circ} \mathrm{C} \mathrm{h}\right.$ ). (For example, a constant temperature of $10^{\circ} \mathrm{C}$ over 14910 hours corresponds to $\left.100^{\circ} \mathrm{C} \mathrm{h}\right)$. A wind shear estimate of $\tau=\rho C_{10} u_{10}^{2}\left(\mathrm{~N} \mathrm{~m}^{-2}\right)$ with wind150 dependent drag coefficient, $C_{10}$, air density, $\rho$, and wind speed at $10 \mathrm{~m} \mathrm{high,} \mathrm{u}_{10}$, set according to 151 Wüest and Lorke (2003), was averaged over time (December to March) to quantify wind exposure during winter. Estimates for water column stability at the end of summer were 
calculated as Schmidt stability $\left(\mathrm{J} \mathrm{m}^{-2}\right)$. Datasets containing WMDs, temperature-hours, wind exposure, and Schmidt stability were available for a period from 1994 to 2016.

Monitoring profiles allowed for TP content estimates (tons; t) spanning from 1982 to present. The annual $\mathrm{P}$ renewal $\Delta P_{\text {winter }}^{a b s}$ in the upper $15 \mathrm{~m}$ of the water column during convective mixing in winter can be estimated as the difference between the maximum depth-integrated epilimnion TP content after winter $\left(P_{\max }^{15}\right)$ and the TP content remaining at the end of the preceding stratified season $\left(P_{r e m}^{15}\right)$ :

$$
\Delta P_{\text {winter }}^{\text {abs }}[\mathrm{t}]=P_{\max }^{15}-P_{\text {rem }}^{15}
$$

As shown in Müller et al. (2012a), the upper $15 \mathrm{~m}$ of the water column provide a good approximation for the average summer epilimnion and euphotic zone depths (see Fig. S3 for Lake Zug). Ongoing reoligotrophication leads to decreasing TP throughout the entire water column and to strong intra-annual fluctuations in the epilimnion (Fig. 2). Moreover, the decrease of TP in the hypolimnion leads to a decline in $\Delta P_{\text {winter }}^{a b s}$ as well. To correct for these systematics, we express relative TP renewal as

$$
\Delta P_{\text {winter }}[\%]=100 \times \frac{P_{\max }^{15}-P_{\text {rem }}^{15}}{P_{\max }},
$$

where $P_{\max }$ is the TP content of the entire lake at the time when $P_{\max }^{15}$ was estimated. To interpret the physical meaning of the quantity $\Delta P_{\text {winter }}$, two hypothetical extremes are instructive to discuss. First, if convective mixing is not deeper than the defined euphotic depth of $15 \mathrm{~m}$, no $\mathrm{P}$ is supplied from the hypolimnion and $\Delta P_{\text {winter }} \approx 0 \%\left(P_{\max }^{15}\right.$ might still differ slightly from $P_{\text {rem }}^{15}$ due to differences in $\mathrm{P}$ inflow and outflow, or due to $\mathrm{P}$ sedimentation during winter). Second, in the case of full convective mixing, TP concentrations in the lake are homogenized and $\frac{P_{\max }^{15}}{P_{\max }}$ is close to the ratio of the euphotic depth divided by the mean lake depth. If $P_{r e m}^{15}$ is negligible, this ratio $\left(15 \mathrm{~m} / 83 \mathrm{~m}=18 \%\right.$ in Lake $\mathrm{Zug}$ ) indicates the maximum possible value for $\Delta P_{\text {winter }}$ (again neglecting external load, export, and P settling).

For comparison, the expected $\mathrm{P}$ input at a certain WMD was also calculated based on averaged fall TP concentrations (using TP profiles from a base period of 1982 to present). This calculation assumed that TP was completely homogenized in spring down to the WMD. Then, neglecting all 
changes due to inflows, outflows, or net sedimentation during winter, the TP content in the uppermost $15 \mathrm{~m}\left(P_{\max }^{15}{ }^{\prime}\right)$ after mixing could be calculated as

$$
P_{\max }^{15}{ }^{\prime}=P_{W M D} \times \frac{V_{15}}{V_{W M D}}
$$

where $V_{15}$ is the volume of the uppermost $15 \mathrm{~m}, V_{W M D}$ is the volume of the homogenized layer after winter mixing and $P_{W M D}$ is the TP content in this homogenized layer before winter mixing (end of fall) based on the 1982 to 2015 average. The expected $\Delta P_{\text {winter }}[\%]$ can then be calculated using eq. 2 with $P_{\max }^{15}{ }^{\prime}$ instead of $P_{\max }^{15}$ and using the averaged remaining TP from the upper $15 \mathrm{~m}$ in fall as $P_{r e m}^{15}$. The maximum value of $17.2 \%$ at $197 \mathrm{~m}$ mixing depth is slightly less than the ratio of the epilimnion depth to the mean lake depth ( 18\%), since the term $P_{r e m}^{15}$ in eq. 2 is not exactly zero. Using TP profiles from other lakes, the same relationship can be established for other systems with different morphology. We decided to compare Lake Zug with two additional deep Swiss lakes with highly variable WMD and irregularly occurring complete homogenization in winter (Lake Zurich and Lake Geneva) and with Lake Tanganyika, a typical example of a deep African lake with vertical mixing (here driven by wind instead of convection) as the main driver for productivity. TP profiles from 1982-2015 (Lake Zug), 1982-2013 (Lake Zürich), and 1982-2012 (Lake Geneva) were used for the comparison. For Lake Tanganyika, the calculation is based on one single $\mathrm{PO}_{4}$ profile taken from Edmond et al. (2003). Calculations based on another published profile from Degens et al. (1971) gave very similar results.

\section{One-dimensional modelling}

The one-dimensional lake model SIMSTRAT (Goudsmit et al. 2002) was used to predict thermal structure and winter mixing behaviour of Lake Zug. SIMSTRAT is a buoyancy-extended k- $\varepsilon$ lake model with additional parameterization for internal seiches. Previous studies have used SIMSTRAT to interpret climate change, heat budgets, and WMD in lakes (Peeters et al. 2002; Fink et al. 2014; Schwefel et al. 2016; Gaudard et al. 2017). Simulations used a model period ranging from 10 June 1993 to 1 January 2017 with an initial 18 months period treated as a spinup phase. The model results based on meteorological inputs between 1995 and 2017 (described above) were compared with monitoring profiles.

Secchi depth measurements were used to estimate absorption of short wavelength radiation following methods used in previous modelling studies for Lake Geneva (Schwefel et al. 2016). 
The wind drag coefficient $\mathrm{C}_{10}$ was treated as a constant. Using a wind-dependent $\mathrm{C}_{10}$ as input (Wüest and Lorke 2003) resulted in higher root-mean square errors after calibration. Higher errors probably resulted from low wind speeds causing large uncertainties in estimates for $\mathrm{C}_{10}$. Slight differences between wind speeds measured at the meteorological station and the wind directly affecting the lake surface also contribute to these errors. Because of Lake Zug's long ( 14.2 yr) residence time and because most inflow remains in the epilimnion (not affecting the deep water), the simulation ignored inflows and outflow. This procedure was validated for Lake Geneva, a lake with an even shorter residence time than Lake Zug (Schwefel et al. 2016).

Lake Zug's salinity gradient poses a challenge in nutrient and hydrodynamic modelling of the water column because it causes the lake to remain stratified throughout the winter. Since sources and sinks for salinity are not well quantified, salinity estimates provided by one-dimensional numerical models cannot be easily validated by monitoring data. For the model, we assumed a constant salinity profile for the entire modelling period in order to assure chemical stratification in deeper layers of Lake Zug during the critical late winter and spring period. It was set to the average salinity gradient after winter mixing during the 1995 to 2016 modelling period.

\section{Climate change scenarios}

To determine water column response to changing climatic conditions, the model used input temperatures predicted according to regional variants of IPCC climate scenarios for central Switzerland (CH2011 2011). Other forcing parameters such as wind or cloud cover were held constant since climate scenarios offer no consistent predictions for those parameters. A total of ten different model runs were performed. These included a reference run for the years 1995 to 2016, and nine model runs with temperatures predicted around the years 2035, 2060, and 2085 according to IPCC emission scenarios $\mathrm{A} 2, \mathrm{~A} 1 \mathrm{~B}$, and $\mathrm{RCP} 3 \mathrm{CP}$. Table 1 lists the mean temperature increases for each scenario. To set up realistic boundary conditions, the model started at year 1993 and run up until 1995 as a spin-up period. The year 1993 was selected based on the 234 availability of meteorological data without major data gaps. Predicted seasonal changes in air 235 temperatures (Table S1) were added to the measured temperatures of the reference scenario 19952362016 to create air temperatures for the additional model runs under warming climate. 


\section{Phosphorus budget}

As shown in Fig. 2a, the TP content of Lake Zug decreased over the last 35 years by $\sim 60 \%$, from more than $600 \mathrm{t}$ in 1980 to $\sim 250 \mathrm{t}$ in 2015. Measured TP profiles taken from the deepest location of the lake indicate an average decrease of $-16 \mathrm{t} \mathrm{yr}^{-1}$ between 1982 and 2006 and of $-5.5 \mathrm{t} \mathrm{yr}^{-1}$ since 2006 (Fig. 2). The change in the lake's TP content is a function of input sources ( $\mathrm{P}_{\text {in }}$; from rivers, atmospheric deposition, and direct sewage treatment plant releases), net sedimentation (NS), and TP outflow via the River Lorze $\left(\mathrm{P}_{\text {out }}\right)$ :

$$
\frac{\Delta P}{\Delta t}=P_{\text {in }}-P_{\text {out }}-N S .
$$

Each of these terms were determined to provide separate empirical TP estimates independent of those from water column profiles. Between 2005 and 2015, the annual TDP load from tributaries including precipitation, storm water overflow and direct inputs reached $5.9 \pm 1.1 \mathrm{t} \mathrm{yr}^{-1}$ while annual outflow was $6.8 \pm 1.4 \mathrm{t} \mathrm{yr}^{-1}$. Sediment cores indicated a slightly decreasing net sedimentation rate for the same period with a mean value of $8.4 \pm 1.0 \mathrm{t} \mathrm{yr}^{-1}$. Estimation of net sedimentation rates based on the $\mathrm{P}$ budget (eq. 4) yielded a similar value but with larger error (7.5 $\left.\pm 12.0 \mathrm{t} \mathrm{yr}^{-1}\right)$. The theoretical budget calculations thus match observed changes in the lake (observed: -9.8 $\mathrm{t} \mathrm{yr}^{-1}$ since 2016; calculated according to eq. 4: $-9.3 \mathrm{t} \mathrm{yr}^{-1}$ ). Both modelled and observed results indicate that ongoing decline in TP is slow compared to intra-annual fluctuations within the epilimnion (see below). The use of TDP instead of TP from tributaries can partially account for differences in the observed and calculated values. However, although the exact quantification of the fraction of mineralizing particulate $\mathrm{P}$ in the tributaries is not known, several former studies confirmed that its contribution is of minor importance (Gächter and Wehrli 1998; Moosmann et al. 2006).

In the epilimnion, TP decrease is overlaid by strong seasonal dynamics. As indicated in Fig. 1c, dissolved $\mathrm{P}$ is taken up by phytoplankton during stratification, transported as particulate $\mathrm{P}$ in biomass to the hypolimnion (gross sedimentation), and is then replenished by TP-rich hypolimnetic water $\left(\Delta P_{\text {winter }}^{a b s}\right)$ during winter mixing. The average value for $\Delta P_{\text {winter }}^{a b s}$ between 2000 and 2016 was $70 \mathrm{t}$. This upwelling exceeds the annual external load $\left(P_{i n}\right)$ from the catchment by an order of magnitude.

\section{Deep convective winter mixing}


Between 1982 and 2016, WMD fluctuated around a mean depth of $78 \pm 25 \mathrm{~m}$ (Fig. 3a). Notable excursions from the mean value included (1) a deep mixing event in February 2006, when cooling-induced convection extended almost to maximum depth and (2) a significant decrease in deep mixing in the late winters of 2014 and 2015. These two mild winters were preceded by stable lake stratification at the end of autumn. WMD did not correlate with wind exposure $\left(\mathrm{r}^{2}=\right.$ $0.015)$ indicating that convection represents the primary mechanism for winter mixing. This finding is supported by the shallow Monin-Obukhov depth (Fig. S4). However, WMD showed some correlation with higher powers of wind speed integrated over winter periods $\left(\mathrm{r}^{2}=0.38\right.$ for the sixth power). Hence, occasional strong winter wind events contribute to deep mixing while average winds do not play a role at all. As expected, WMD correlated negatively with end of summer stratification (derived from the measured profile in August; $r^{2}=-0.39 ; p=0.02 ;$ Fig. 3c) and with winter temperature $\left(r^{2}=-0.35 ; p=0.04 ;\right.$ Fig. $\left.3 b\right)$. These results are consistent with those from similar analyses of Lake Geneva (Schwefel et al. 2016) which exhibits a strong correlation between winter temperature and WMD $\left(\mathrm{r}^{2}=0.73\right)$, but only a weak correlation between winter wind speed and WMD. One reason for the weaker relationship between Lake Zug's winter temperatures and WMD is its stable chemical stratification, which leaves the water column less susceptible to external forcing. The strong dependency of WMD on autumn stratification may also play an important role.

\section{Winter mixing and phosphorus upwelling}

By the end of winter 2015, WMD reached only $35 \mathrm{~m}$, the shallowest value ever observed during regular monitoring (see above). An extraordinarily warm 2014 followed by a mild 2014/2015 winter contributed to this record. The observed dependency of WMD on stability and winter temperatures also increases the likelihood of shallow WMDs under future climatic conditions. As shown in Fig. 4, a decrease in WMD will affect the amount of TP upwelled to the epilimnion $\left(\Delta P_{\text {winter }}\right)$. Regression of WMD data from 1988 to 2016 (a period for which sufficient WMD and $\mathrm{P}$ data exist), gave the following logarithmic relationship:

$$
\Delta P_{\text {winter }}[\%]=3.5 \ln (W M D-17.4)
$$

294 This relationship describes the estimated TDP upwelling fairly well $\left(\mathrm{r}^{2}=0.62\right)$. 


\section{Model results}

The model was calibrated using the PEST (Model-Independent Parameter Estimation and Uncertainty Analysis) software package (Doherty 2013). Table 2 lists the calibration results for the model parameters. SIMSTRAT reproduced the temperature structure of Lake Zug with a root mean square error (RMSE) of $0.80{ }^{\circ} \mathrm{C}$. The simulation gave RMSE values of $1.76{ }^{\circ} \mathrm{C}$ for the epilimnion, which were considerably higher than those calculated for the hypolimnion $\left(0.42{ }^{\circ} \mathrm{C}\right)$. Similar to previous 1D-simulations (e.g. Perroud et al. 2009), the highest differences were observed for the thermocline. The volume-averaged mean temperature estimate of $5.96{ }^{\circ} \mathrm{C}$ was in excellent agreement with the measured value of $6.00{ }^{\circ} \mathrm{C}$ for the reference period 1995-2016. Modelled WMD values were reasonably consistent with observed values for warmer winters (which gave shallow WMDs), but the model overestimated the number of winters with very deep WMDs. To avoid systematic overestimation of WMD, winters in which modelled WMD exceeded $120 \mathrm{~m}$ (five winters in total) were omitted from further analysis.

For the IPCC climate scenario A2, which predicts the greatest increases in air temperature, the simulated WMD decreases from $78 \mathrm{~m}$ in the reference scenario to $76 \mathrm{~m}$ in 2035, $72 \mathrm{~m}$ in 2060, and $65 \mathrm{~m}$ in 2085. Results based on scenario A1B resembled those based on scenario A2 but showed less pronounced trends. For example, A2 assumptions result in a $65 \mathrm{~m}$ maximum WMD by 2085 , whereas A1B assumptions estimate a $68 \mathrm{~m}$ maximum WMD for the same time interval (Fig. 3a). The WMD results modelled using RCP3CP assumptions do not change for any of the modelled time periods. Volume-averaged lake temperatures increase from $5.96^{\circ} \mathrm{C}$ to up to $7.19^{\circ} \mathrm{C}$ in 2085 for scenario A2. For other climate scenarios, the results were similar but changes at the end of the century were less pronounced than those predicted for scenario A2. Scenarios A1B and RCP3CP predict respective mean temperatures of $7.00^{\circ} \mathrm{C}$ and $6.37^{\circ} \mathrm{C}$ by 2085 (Table 1). Neither of these showed significant divergence from respective 2060 estimates.

\section{DISCUSSION}

\section{Importance of WMD for $\mathrm{P}$ input into the epilimnion}

Since the 1980s, TP content declined in Lake Zug due to a ban of P in detergents and reduced application of fertilizers in agriculture. This trend appears throughout the water column but is 
overlaid by strong seasonal variation in the epilimnion, where winter mixing causes a pronounced maximum in TP followed by a continuous decline during the subsequent stratification period (Fig. 2). The degree of TP depletion observed at the end of the stratified season illustrates the critical role of internal upwelling by winter mixing in supplying nutrients for biomass production. Winter mixing specifically supplies an estimated $70 \mathrm{t} \mathrm{yr}^{-1}$ of TP to the epilimnion, an amount that greatly exceeds the annual external input of $\sim 6 \mathrm{t} \mathrm{yr}^{-1}$.

\section{Winter mixing depth and meteorological forcing}

Although the dependency of WMD on winter temperatures was found to be weaker in Lake Zug than in Lake Geneva (Schwefel et al. 2016), WMD still correlated weakly with winter temperatures. Autumn stratification has a much stronger impact. Since summer and autumn temperatures strongly affect autumn stratification, winter temperature variation is not sufficient for explaining variation of winter mixing of Lake Zug. Wind drives winter mixing in shallow lakes and plays an important role in generating hypolimnetic currents in deep lakes (MacIntyre et al. 1999; Rueda et al. 2003), which in turn cause vertical diffusivity (Wüest and Lorke 2003). While strong wind events may have some influence on WMD, the influence of average wind speed however is negligible compared to that of autumn stratification. The weaker than expected influence of meteorological conditions on WMD may partly result from the weak but permanent salinity gradient. This gradient dampens WMD fluctuations and prevents winter mixing from extending below depths of $\sim 100 \mathrm{~m}$, except in the case of extreme cold events such as winter 2005/06. Given ongoing climate warming, the increase in both autumn stratification and winter temperatures will continue to reduce WMD. According to the model, the IPCC climate scenario A2 predicts the largest increase in air temperatures, which will cause a WMD decrease from the present average of $78 \mathrm{~m}$ to $65 \mathrm{~m}$ by 2085 .

\section{Effects of changing WMD on the P budget}

347 According to eq. 5, this decrease in WMD results in lower epilimnetic TP concentrations after 348 winter mixing (Fig. 4a). The relationship between TP upwelling and mixing depth can 349 alternatively be calculated from the average TP concentration profile at the end of autumn (red line in Fig. 4a). The values derived from this method were generally lower than the observed values. This systematic difference is due to $\mathrm{P}$ inflow from the catchment in winter and due to turbulent upward diffusion. Such additional terms are included in the observed $\Delta P_{\text {winter }}$ (data 
points in Fig. 4; eq. 5), but not in calculations using the averaged end-autumn TP profiles and

As a result of ongoing oligotrophication, the annual mean total TP content of Lake Zug declined to $\sim 250 \mathrm{t}$ with a current average epilimnion TP concentration of $64 \mathrm{mg} \mathrm{m}^{-3}$ in spring. Assuming no changes in external TP inputs, and using the results from Fig. $4 \mathrm{a}$, the model runs predict a $\sim 5$ $\mathrm{mg} \mathrm{m}^{-3}$ climate-induced decrease in epilimnetic TP concentration by 2085 . While the average decreases in TP seem to be low, declining epilimnetic $\mathrm{P}$ values are especially pronounced in the case of shallow WMDs (Fig. 4a). While WMD values have fallen below $40 \mathrm{~m}$ only twice since 1982 (in 2014 and 2015), extremely shallow WMDs are predicted to become more common with higher temperatures (e.g. in seven out of 22 winters by 2085 according to IPCC scenario A2B; Fig. 3a). For extreme WMD shallowing, the predicted decrease in TP is substantial: a $40 \mathrm{~m}$ mixing depth, for example, causes a $24 \%$ decline from average epilimnetic TP values.

\section{Comparison with other lakes}

With the same method, similar relationships can be established for other lakes given the bathymetry and P profiles (Fig. 4b). Assuming a homogeneous mixing and an epilimnion thickness of $15 \mathrm{~m}$, Lake Geneva shows a behaviour strikingly similar to that of Lake Zug. Specifically, if WMD of Lake Geneva reaches $40 \%$ of the maximum lake depth, convective mixing entrains $80 \%$ of the lake's TP content and distributes it into the epilimnetic P reservoir. Therefore, a further increase in WMD exerts only a minor influence on the epilimnetic $\mathrm{P}$ budgets of Lake Geneva. The mean WMD of Lake Geneva currently reaches $\sim 180 \mathrm{~m}$, or $58 \%$ of the maximum depth (Schwefel et al. 2016) and is therefore below the depth at which WMD can significantly affect $\mathrm{P}$ supply into the epilimnion. For comparison, in Lake Zug, WMD advances to an average depth of $78 \mathrm{~m}$ (39\% of the maximum) where small variations still exert a strong influence on TP in the epilimnion (Fig. 4a). A predicted decline or shallowing of the WMD by 13 $\mathrm{m}$ or $6 \%$ leads to a predicted decrease in epilimnetic TP upwelling of $7 \%$. In Lake Geneva, a 6 $\%$ decrease in WMD would result in only a $4 \%$ change of TP upwelling.

The relationship between nutrient input into the upper layer of Lake Tanganyika and mixing resembles that of temperate lakes investigated in this study. Our assumptions (e.g. an epilimnion depth of $15 \mathrm{~m}$ and horizontally homogenous mixing throughout the lake area) however do not apply to such a lake. Values for Lake Tanganyika should only be interpreted as a sensitivity 
measure of the lake experiencing changes in the deep mixing during the dry season. Compared to Lake Zug, Lake Tanganyika (1470 m deep) is permanently stratified and mixes seasonally down to 200 to $300 \mathrm{~m}$ depth (Coulter 1968; O'Reilly et al. 2003). In lakes where wind is the dominant driver of water column mixing, increased surface temperatures cause shallower mixing depths due to stronger surface stratification. Therefore, observational evidence indicates that mixing depths may have decreased for Lake Tanganyika as well even if convection is not the dominant driver of vertical mixing in this system (O'Reilly et al. 2003). A reduction in WMD by $\sim 100 \mathrm{~m}$, as proposed by O'Reilly et al. (2003) would cause a decline in $\Delta \mathrm{P}_{\text {winter }}$ from $53 \%$ to $34 \%$ of the maximal possible input. This decline exceeds that predicted for Lake Zug by a factor of almost three assuming the same changes in relative mixing depth.

The deepest parts of Lake Zürich have TP concentrations up to 15 times higher than the overall volume average (Fig. 4b). This strong TP gradient in the water column explains the difference between Lake Zürich and the other lakes shown in Fig. 4b. Due to warmer temperatures in the last few years, the WMD of Lake Zürich ranged between 60 and 100 m (i.e. 44 to $73 \%$ of maximum lake depth). In contrast, the lake mixed almost completely on a regular basis before the 1990s (Yankova et al. 2017). As shown in Fig. 4b, this corresponds to a decrease in TP upwelling to the epilimnion from the hypolimnion of up to $40 \%$. Yankova et al. (2017) investigated dissolved inorganic P patterns in Lake Zürich since 1977 and found an even greater decrease. The results however are not directly comparable to those reported here since dissolved inorganic $\mathrm{P}$ in Lake Zürich is strongly influenced by the prevalent and predominant cyanobacterium Planktothrix rubescens. Regardless of whether TP or dissolved inorganic P is considered, the decrease in WMD over the last few years has caused a significant reduction in P upwelling to the productive surface layer and has thus enhanced the ongoing oligotrophication.

\section{Conclusion and Outlook}

The four examples described above illustrate that shifts in winter mixing depth can lead to very different outcomes depending on the lake system considered. These differences however can be explained by basic factors such as TP profiles throughout the water column, lake bathymetry, and relative mixing depth. In general, climate warming will result in reduced nutrient availability in spring which is the limiting factor for primary production. Hence, reduced WMD will - in parallel with the ongoing reoligotrophication - lead to a reduction in algal growth in lakes. 
However, changes in nutrient availability may also cause shifts in phytoplankton communities, which in turn affect nutrient budgets. These can cause still even more complex nutrient level responses to climate warming. This study also focused solely on TP response in the epilimnion, contrasting trends may occur in the hypolimnion. Reduced WMD leads to accumulation of TP in deeper layers (Yankova et al. 2017) and may cause hypoxic or even anoxic conditions that can enhance P release from lake sediments (O'Reilly et al. 2003; Sahoo et al. 2013; Schwefel et al. 2016). While this mechanism would not affect primary production in Lake Zug during periods when mixing reaches depths of only $\sim 70 \mathrm{~m}$, extremely cold winters could cause occasional deep mixing that would transport significant amounts of TP into the epilimnion. By contrast, mild winters, which are predicted to occur more frequently in the future, may cause the opposite cascade of shallow WMD leading to limited epilimnetic $\mathrm{P}$ input and associated reduction of primary productivity in spring. With reduced nutrient input during winter mixing, inputs from the catchment might become more influential than they are in the current system. Either way, climate change will introduce greater variation in mixing depths, epilimnetic TP concentrations, and primary productivity.

\section{ACKNOWLEDGMENTS}

We sincerely thank then anonymous reviewers and the editor for their valuable comments. In addition, we are grateful to René Gächter for valuable comments to an earlier version of the manuscript. We also acknowledge the support of the Amt für Umweltschutz Zug, especially Bruno Mathis and Peter Keller, who provided observational data from Lake Zug. Long-term monitoring data for Lake Geneva were provided by the Commission International pour la Protection des Eaux du Léman (CIPEL) and by the SOERE OLA Information System (http://siola.inra.fr), INRA Thonon-les-Bains. Data from Lake Zürich were provided by AWEL Zürich. The CH2011 climate predictions were obtained from the Center for Climate Systems Modeling (C2SM; www.ch2011.ch). Meteorological data of this study are archived and distributed by the Swiss Federal Office of Meteorology and Climatology, MeteoSwiss (obtained via their data portal, IDAWEB). Additional information on the data can be provided on request by alfred.wueest@eawag.ch. The source code for SIMSTRAT can be accessed through the archived GIT repository (link: https://github.com/adrien-ga/Simstrat-BSIW/tree/v1.3, DOI:10.5281/zenodo.841084). The first author was supported by Swiss National Science Foundation grants 200021_146652 and 200020_165517.

We dedicate this article to the memory of our friend and colleague Adrien Gaudard who unexpectedly passed away after a tragic avalanche accident. 


\section{REFERENCES}

Anneville O, Gammeter S, Straile D (2005) Phosphorus decrease and climate variability: mediators of synchrony in phytoplankton changes among European peri-alpine lakes. Freshw Biol 50:17311746. doi: 10.1111/j.1365-2427.2005.01429.x

Anneville O, Ginot V, Angeli N (2002) Restoration of Lake Geneva: Expected versus observed responses of phytoplankton to decreases in phosphorus. Lakes Reserv Res Manag 7:67-80. doi: 10.1046/j.1440-169X.2002.00179.x

AquaPlus (2001) Entwicklung des Gesamtphosphors im Zugersee anhand der im Sediment eingelagerten Kieselalgen. Baudirektion des Kantons Zug, Amt für Umweltschutz, Zug

CH2011 (2011) Swiss Climate Change Scenarios CH2011. C2SM, MeteoSwiss, ETH, NCCR Climate, and OcCC

Coulter GW (1968) Thermal stratification in the deep hypolimnion of Lake Tanganyika. Limnol Oceanogr 13:385-387. doi: 10.4319/lo.1968.13.2.0385

De Pinto JV, Young TC, Mcllroy LM (1986) Great lakes water quality improvement. Environ Sci Technol 20:752-759. doi: 10.1021/es00150a001

Degens ET, Von Herzen RP, Wong H-K (1971) Lake Tanganyika: water chemistry, sediments, geological structure. Naturwissenschaften 58:229-241

Dillon PJ, Rigler FH (1974) The phosphorus-chlorophyll relationship in lakes. Limnol Ocean 19:767-773. doi: 10.4319/lo.1974.19.5.0767

Doherty J (2013) PEST: Software for model-independent parameter estimation, Watermark Numerical Computing, Brisbane

Ficker H, Luger M, Gassner H (2017) From dimictic to monomictic: Empirical evidence of thermal regime transitions in three deep alpine lakes in Austria induced by climate change. Freshw Biol 62:13351345. doi: 10.1111/fwb.12946

Finger D, Wüest A, Bossard P (2013) Effects of oligotrophication on primary production in peri-alpine lakes. Water Resour Res 49:4700-4710. doi: 10.1002/wrcr.20355

Fink G, Schmid M, Wahl B, Wolf T, Wüest A (2014) Heat flux modifications related to climate-induced warming of large European lakes. Water Resour Res 50:2072-2085. doi: 10.1002/2013WR014448

Gächter R, Wehrli B (1998) Ten years of artificial mixing and oxygenation: No effect on the internal phosphorus loading of two eutrophic lakes. Environ Sci Technol 32:3659-3665. doi: 10.1021/es980418।

Gaudard A, Schwefel R, Råman Vinnå L, Schmid M, Wüest A, Bouffard, D (2017) Optimizing the parameterization of deep mixing and internal seiches in one-dimensional hydrodynamic models: 
a case study with Simstrat v1.3. Geosci Model Dev 10:3411-3423. doi: 10.5194/gmd-10-34112017

Goudsmit GH, Burchard H, Peeters F, Wüest A (2002) Application of k- $\epsilon$ turbulence models to enclosed basins: The role of internal seiches. J Geophys Res 107:3230. doi: 10.1029/2001JC000954

Holzner CP, Aeschbach-Hertig W, Simona M, Veronesi M, Imboden D, Kipfer R (2009) Exceptional mixing events in meromictic Lake Lugano (Switzerland/Italy), studied using environmental tracers. Limnol Oceanogr 54:1113-1124. doi: 10.4319/lo.2009.54.4.1113

Imboden DM, Stotz B, Wüest A (1988) Hypolimnic mixing in a deep alpine lake and the role of a storm event. Int Ver Für Theor Angew Limnol Verhandlungen 23:67-73

Jeppesen E, Søndergaard M, Jensen JP, Havens K, Anneville O, Carvalho L, Coveney M, Deneke R, Doukulil $M$, Foy $B$ (2005) Lake responses to reduced nutrient loading-an analysis of contemporary longterm data from 35 case studies. Freshw Biol 50:1747-1771

Lepori F, Bartosiewicz M, Simona M, Veronesi M (2018) Effects of winter weather and mixing regime on the restoration of a deep perialpine lake (Lake Lugano, Switzerland and Italy). Hydrobiologia 824:229-242. doi: 10.1007/s10750-018-3575-2

Maclntyre S, Flynn KM, Jellison R, Romero JR (1999) Boundary mixing and nutrient fluxes in Mono Lake, California. Limnol Oceanogr 44:512-529

Makarewicz JC (1993) Phytoplankton biomass and species composition in Lake Erie, 1970 to 1987. J Gt Lakes Res 19:258-274

Moosmann L, Gächter R, Müller B, Wüest A (2006) Is phosphorus retention in autochthonous lake sediments controlled by oxygen or phosphorus? Limnol Oceanogr 51:763-771

Moss B, Kosten S, Meerhof M, Battarbee R, Jeppesen E, Mazzeo N, Havens K, Lacerot G, Liu Z, De Meester L (2011) Allied attack: climate change and eutrophication. Inland Waters 1:101-105. doi: 10.5268/IW-1.2.359

Müller B, Bryant LD, Matzinger A, Wüest A (2012a) Hypolimnetic oxygen depletion in eutrophic lakes. Environ Sci Technol 46:9964-9971. doi: 10.1021/es301422r

Müller B, Gächter R, Wüest A (2014) Accelerated water quality improvement during oligotrophication in peri-alpine lakes. Environ Sci Technol 48:6671-6677. doi: 10.1021/es4040304

Müller B, Och L, Wüest A (2012b) Entwicklung des Phosphorhaushalts und der Sauerstoffzehrung im Sempacher- und Baldeggersee. EAWAG, Kastanienbaum

Müller B, Wüest A (2016) Abnahme des Phosphorgehalts im Zugersee Stand 2016. EAWAG, Kastanienbaum

North RP, North RL, Livingstone DM, Köster O, Kipfer R (2014) Long-term changes in hypoxia and soluble reactive phosphorus in the hypolimnion of a large temperate lake: Consequences of a climate regime shift. Glob Change Biol 20:811-823. doi: 10.1111/gcb.12371 
O’Reilly CM, Alin SR, Plisnier P-D, Cohen A, McKee B (2003) Climate change decreases aquatic ecosystem productivity of Lake Tanganyika, Africa. Nature 424:766-768

O’Reilly CM, Sharma S, Gray DK, et al (2015) Rapid and highly variable warming of lake surface waters around the globe. Geophys Res Lett 42:10773-10781. doi: 10.1002/2015GL066235

Peeters F, Livingstone DM, Goudsmit G-H, Kipfer R, Forster R (2002) Modeling 50 years of historical temperature profiles in a large central European lake. Limnol Oceanogr 47:186-197. doi: 10.4319/lo.2002.47.1.0186

Perroud M, Goyette S, Martynov A, Beniston M, Anneville O (2009) Simulation of multiannual thermal profiles in deep Lake Geneva: A comparison of one-dimensional lake models. Limnol Oceanogr Methods 54:1574-1594

Rogora M, Buzzi F, Dresti C, Leoni B, Lepori F, Mosello R, Patelli M, Salamaso N (2018) Climatic effects on vertical mixing and deep-water oxygen content in the subalpine lakes in Italy. Hydrobiologia 824:33-50. doi: 10.1007/s10750-018-3623-y

Rueda FJ, Schladow G, Pálmarsson S (2003) Basin-scale internal wave dynamics during a winter cooling period in a large lake. J Geophys Res Oceans 108(C3):3097. doi: 10.1029/2001JC000942

Sahoo GB, Schladow SG, Reuter JE, Coats R, Dettinger M, Riverson J, Wolfe B, Costa-Cabral M (2013) The response of Lake Tahoe to climate change. Clim Change 116:71-95. doi: 10.1007/s10584-0120600-8

Salmaso N, Boscaini A, Capelli C, Cerasino L (2018) Ongoing ecological shifts in a large lake are driven by climate change and eutrophication: evidences from a three-decade study in Lake Garda. Hydrobiologia 824:177-195. doi: 10.1007/s10750-017-3402-1

Schindler DW (2006) Recent advances in the understanding and management of eutrophication. Limnol Oceanogr 51:356-363. doi: 10.4319/lo.2006.51.1_part_2.0356

Schmid M, Hunziker S, Wüest A (2014) Lake surface temperatures in a changing climate: A global sensitivity analysis. Clim Change 124:301-315. doi: 10.1007/s10584-014-1087-2

Schwefel R, Gaudard A, Wüest A, Bouffard D (2016) Effects of climate change on deep-water oxygen and winter mixing in a deep lake (Lake Geneva) - Comparing observational findings and modeling. Water Resour Res 52:8811-8826. doi: 10.1002/2016WR019194

Schwefel R, Steinsberger T, Bouffard D, Bryant LD, Müller B, Wüest A (2018) Using small-scale measurements to estimate hypolimnetic oxygen depletion in a deep lake. Limnol Oceanogr 63:S54-S67. doi: 10.1002/Ino.10723

Simona M (2003) Winter and spring mixing depths affect the trophic status and composition of phytoplankton in the northern meromictic basin of Lake Lugano. J Limnol 62:190-206. doi: 10.4081/jlimnol.2003.190

Straile D, Jöhnk K, Rossknecht H (2003) Complex effects of winter warming on the physicochemical characteristics of a deep lake. Limnol Oceanogr 48:1432-1438. doi: 10.4319/lo.2003.48.4.1432 
2

3

4553

554

555

9556

10557

11558

12

13

559

560

16

17561

18562

19

20
Vollenweider RA (1968) Scientific fundamentals of the eutrophication of lakes and flowing waters, with particular reference to nitrogen and phosphorus as factors in eutrophication. OECD Paris Tech Rep 5CSI6827

Wüest A, Gloor M (1998) Bottom Boundary Mixing: the Role of Near-Sediment Density Stratification. In: Imberger J (ed) Physical Processes in Lakes and Oceans. Coastal and Estuarine Studies 54. Academic Press, New York, 485-502

Wüest A, Lorke A (2003) Small-scale hydrodynamics in lakes. Annu Rev Fluid Mech 35:373-412. doi: 10.1146/annurev.fluid.35.101101.161220

Yankova Y, Neuenschwander S, Köster O, Posch T (2017) Abrupt stop of deep water turnover with lake warming: Drastic consequences for algal primary producers. Sci Rep 7:13770 


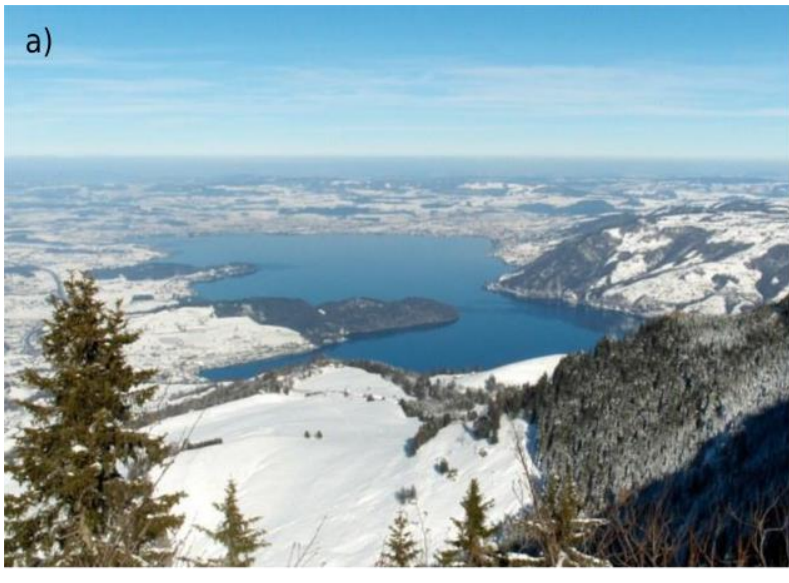

c)

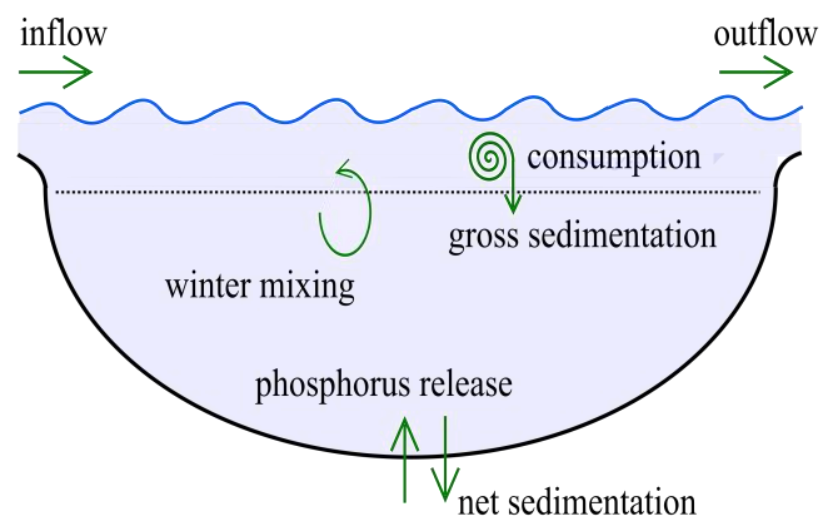

Fig. 1. a) Photo of Lake Zug. b) Illustration of the nutrient exchange during winter mixing. During winters with shallow mixing, fewer nutrients are transported into the epilimnion. c) Schematic diagram illustrating the relevant processes affecting the epilimnetic $\mathrm{P}$ budget of lakes. d) Map of Lake Zug (with arrow indicating outflow) along with the location of the meteorological station and the sampling site for the deepest location in the lake (map data from Swisstopo DV 5704000 000, reproduced with permission from Swisstopo / JA100119). The bottom right corner shows a map of Switzerland with the position of Lake Zug marked as black dot. 
1

2

3

4

5

6

7

8
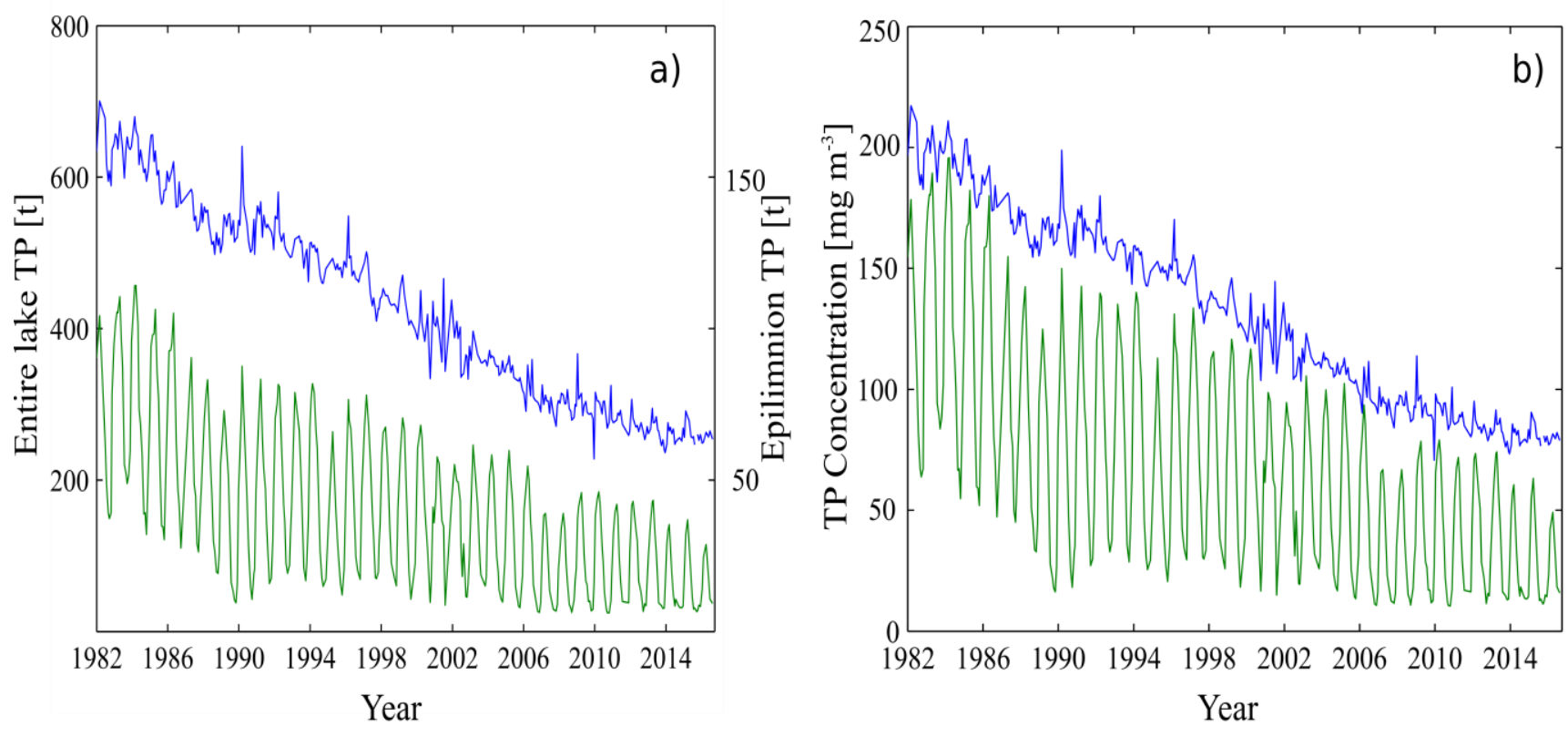

573 Fig. 2. TP content (a) and volume-weighted average TP concentration (b) for Lake Zug over the entire water column 574 (blue) and the epilimnion (green) from 1982 to present. 

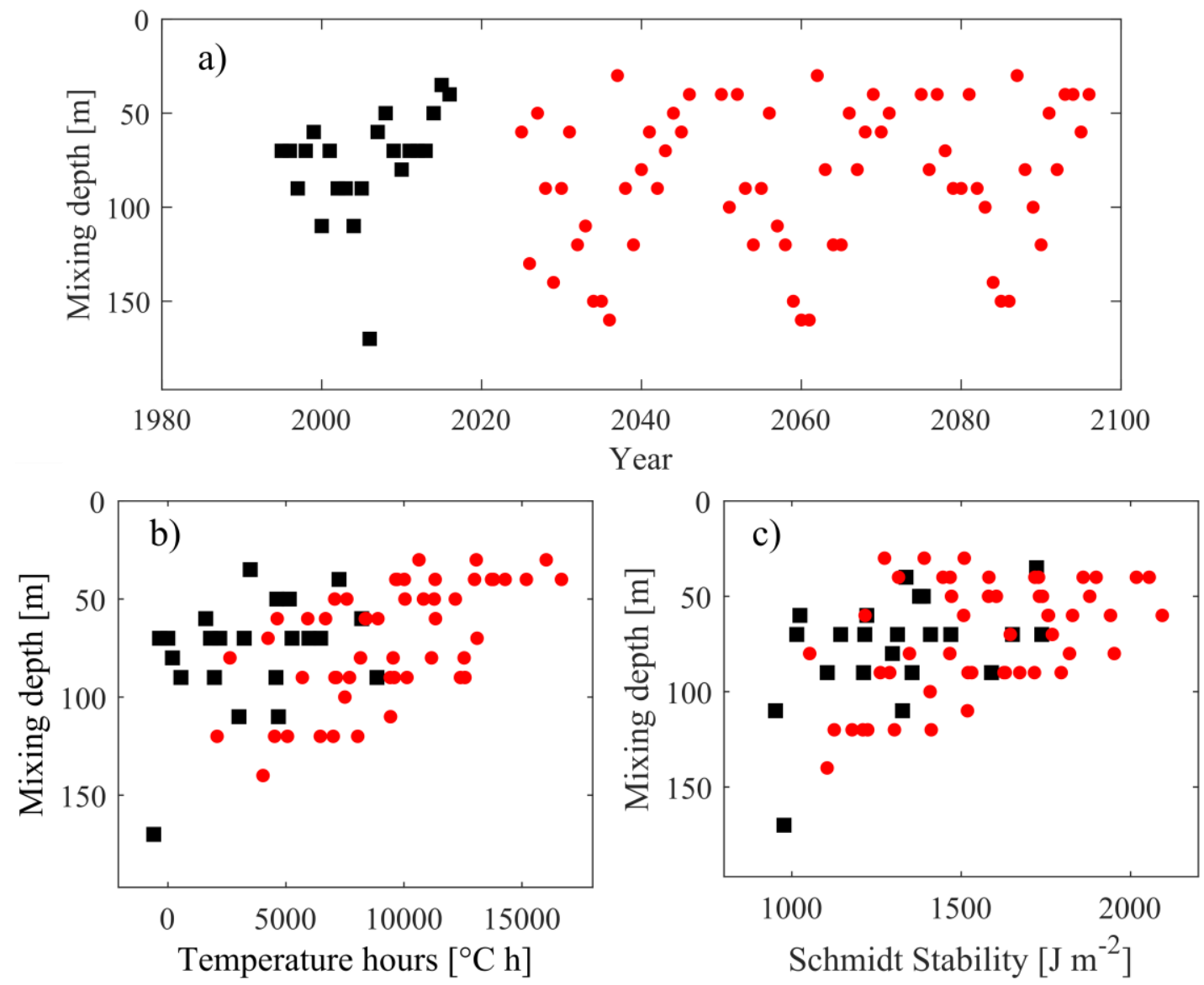

Fig. 3. (a) Time series for observed winter mixing depth (WMD) 1995-2016 (black squares). Red circles represent the model results for the same period under increased air temperatures expected by 2035, 2060 and 2085 according to the IPCC climate scenario A2. (b) WMD as a function of temperature hours (as time integral of the temperature relative to $0{ }^{\circ} \mathrm{C}$ over the winter period), and (c) WMD as a function of Schmidt stability at the end of summer (August). As in panel a, black squares refer to the observed values, red circles represent model results. 

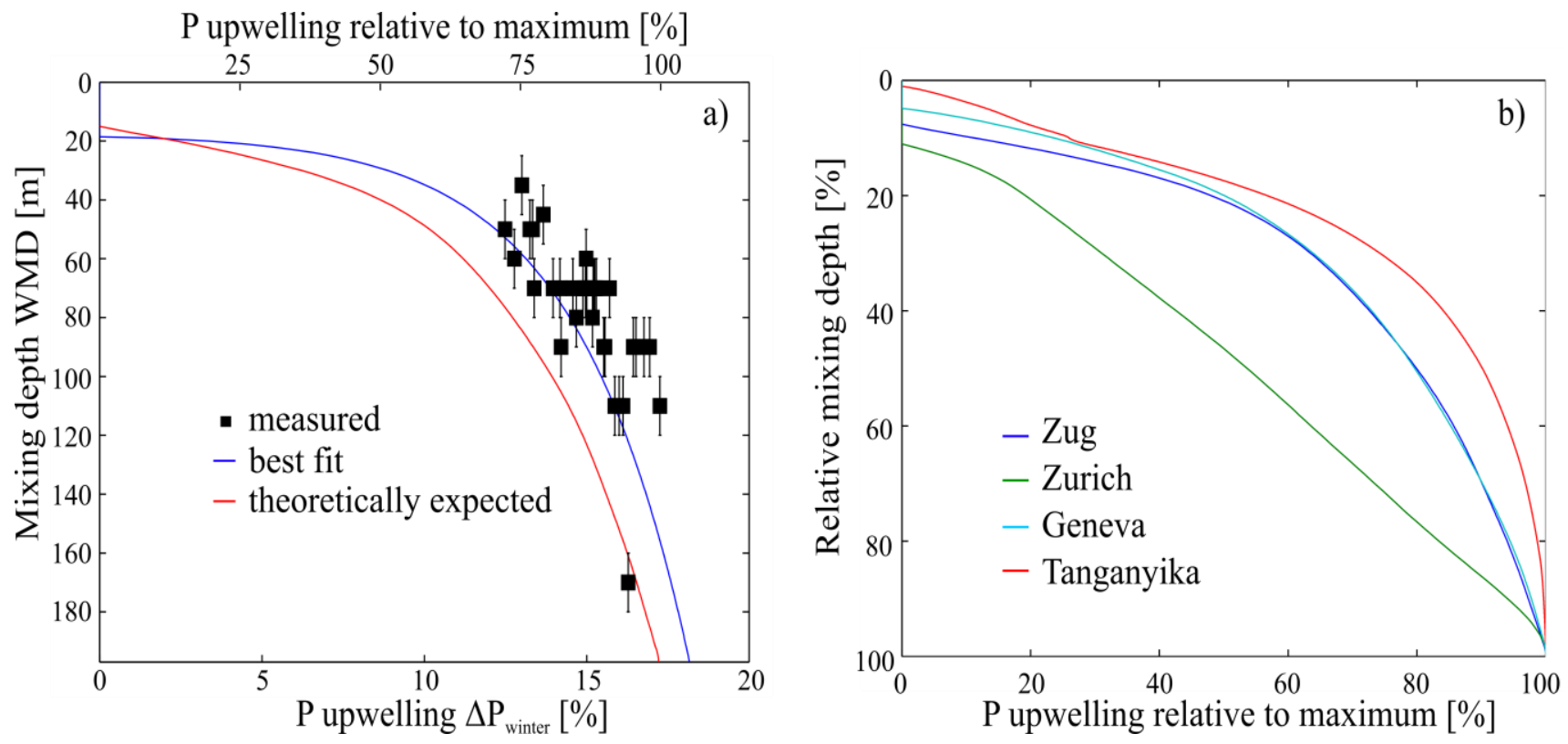

582 Fig. 4. a) Measured $\Delta P_{\text {winter }}$ for Lake Zug as a function of winter mixing depth (WMD; black dots). The blue line shows the logarithmic fit $\Delta P_{\text {winter }}[\%]=3.5 \ln (W M D-17.4)$. The red line shows expected phosphorus upwelling (see methods section for calculation). b) Relative P flux into the upper $15 \mathrm{~m}$ of Lakes Zug, Zürich, Geneva, and Tanganyika as a function of the relative depth (maximum depth $=100 \%$ ). The maximum TP input corresponds to complete homogenization of the lake. 
4587 Table 1. Mean air temperature increase, $\mathrm{T}_{\text {air }}\left({ }^{\circ} \mathrm{C}\right)$, volume-averaged annual mean lake temperatures $\overline{\mathbf{T}}\left({ }^{\circ} \mathrm{C}\right)$, and

5588 winter mixing depth, WMD (m), for different IPCC scenarios. Table S1 lists the seasonal variation in air 6589 temperatures.

7

\begin{tabular}{|c|c|c|c|c|c|c|c|c|c|c|c|}
\hline & \multicolumn{2}{|c|}{$\begin{array}{c}\text { Reference } \\
\text { (1995 to 2016) }\end{array}$} & \multicolumn{3}{|c|}{2035} & \multicolumn{3}{|c|}{2060} & \multicolumn{3}{|c|}{2085} \\
\hline & \multirow{2}{*}{\multicolumn{2}{|c|}{ 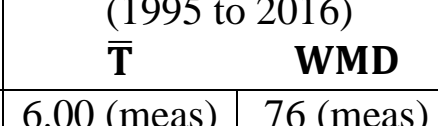 }} & \multirow{2}{*}{$\begin{array}{c}\mathbf{T}_{\text {air }} \\
+1.06 \\
\end{array}$} & $\overline{\mathbf{T}}$ & \multirow{2}{*}{$\begin{array}{l}\text { WMD } \\
76\end{array}$} & \multirow{2}{*}{$\begin{array}{l}\mathbf{T}_{\text {air }} \\
+2.22\end{array}$} & $\overline{\mathbf{T}}$ & WMD & \multirow{2}{*}{$\begin{array}{c}\mathbf{T}_{\text {air }} \\
+3.74\end{array}$} & $\overline{\mathbf{T}}$ & \multirow{2}{*}{$\frac{\text { WMD }}{65}$} \\
\hline $\begin{array}{|rc|}8 & \text { IPCC } \\
9 & \text { Scenario } \\
10 & \\
11 & \\
12 & \text { A2 } \\
\end{array}$ & \multirow{3}{*}{$\begin{array}{l}0.00 \text { (meas) } \\
5.96(\mathrm{mod})\end{array}$} & & & 6.29 & & & 6.67 & 72 & & 7.19 & \\
\hline \multirow{2}{*}{ 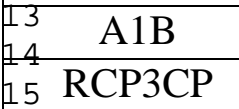 } & & \multirow{2}{*}{78 (mod) } & \multirow{2}{*}{$\begin{array}{l}+1.18 \\
+1.14\end{array}$} & \multirow{2}{*}{$\begin{array}{l}6.33 \\
6.32\end{array}$} & \multirow{2}{*}{$\begin{array}{l}80 \\
81\end{array}$} & \multirow{2}{*}{$\begin{array}{l}+2.27 \\
+1.33\end{array}$} & \multirow{2}{*}{$\begin{array}{l}6.99 \\
6.38\end{array}$} & \multirow{2}{*}{$\begin{array}{l}74 \\
79\end{array}$} & +3.20 & \multirow{2}{*}{$\begin{array}{l}7.00 \\
6.37\end{array}$} & \multirow{2}{*}{$\begin{array}{l}68 \\
80\end{array}$} \\
\hline & & & & & & & & & +1.36 & & \\
\hline
\end{tabular}


Table 2. Non-dimensional calibration parameters used in the SIMSTRAT numerical lake model (Goudsmit et al. 5592 2002)

6

7

\begin{tabular}{|c|l|c|}
\hline Parameter & \multicolumn{1}{|c|}{ Description } & Value [non-dim.] \\
\hline$\alpha$ & Fraction of wind energy transferred to seiche energy & 0.0020 \\
\hline $\mathrm{p}_{1}$ & Correction factor for absorption of infrared radiation & 1.136 \\
\hline $\mathrm{p}_{2}$ & Correction factor for sensible heat flux & 1.286 \\
\hline $\mathrm{q}_{\mathrm{nn}}$ & Distribution coefficient for seiche energy & 1.238 \\
\hline $\mathrm{C}_{10}$ & Wind drag coefficient 10 m above water & 0.0029 \\
\hline
\end{tabular}



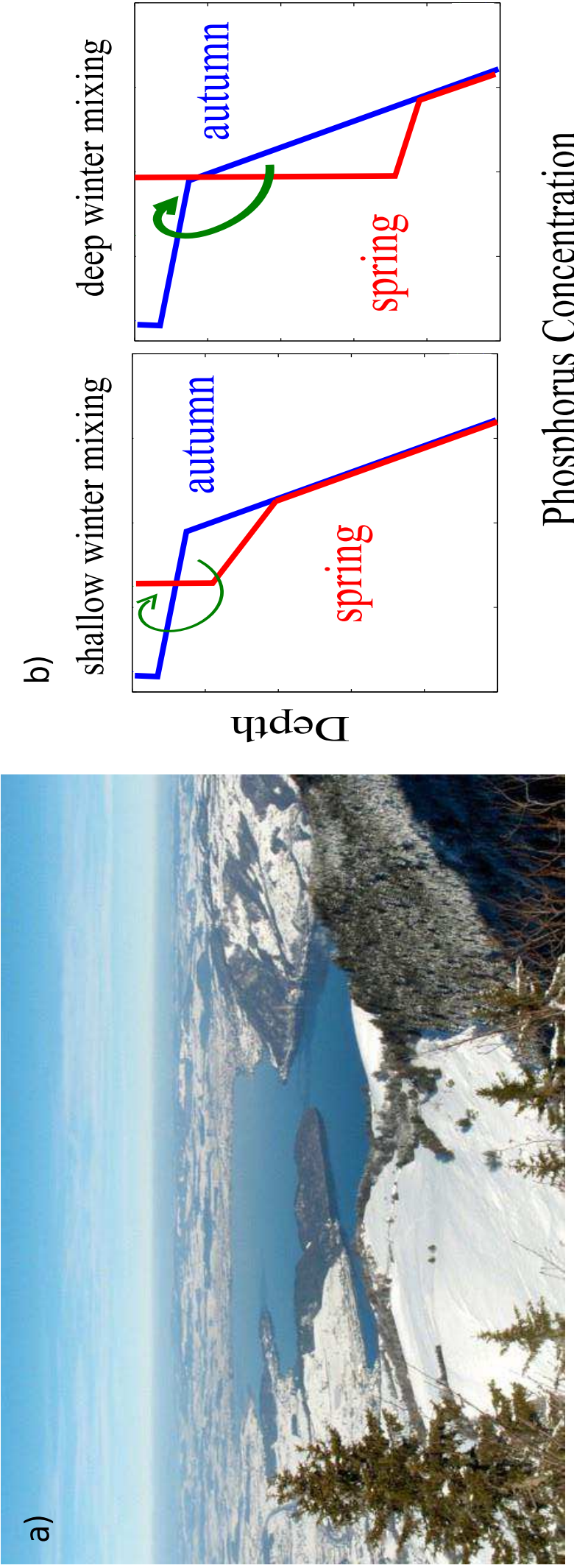
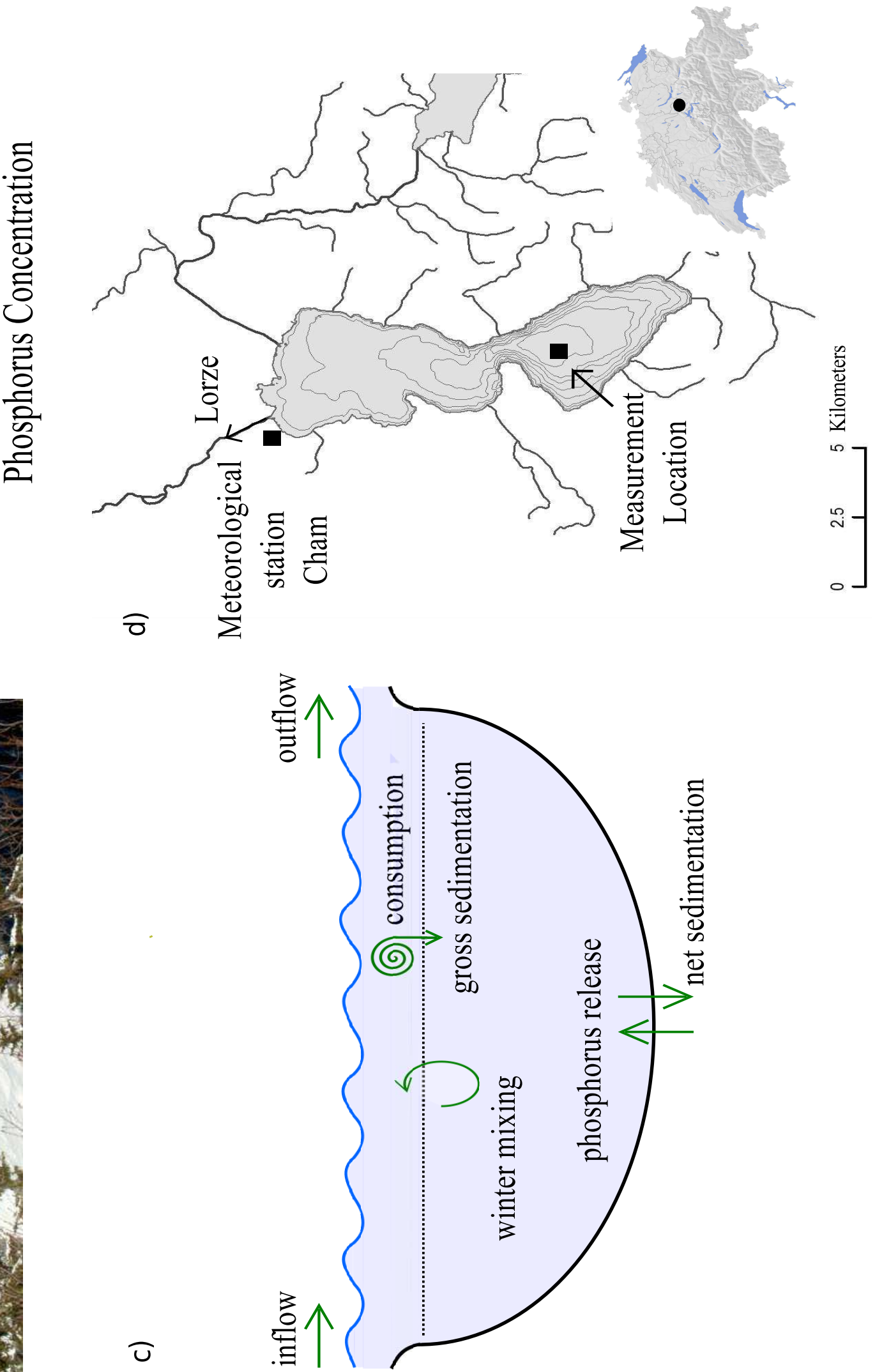

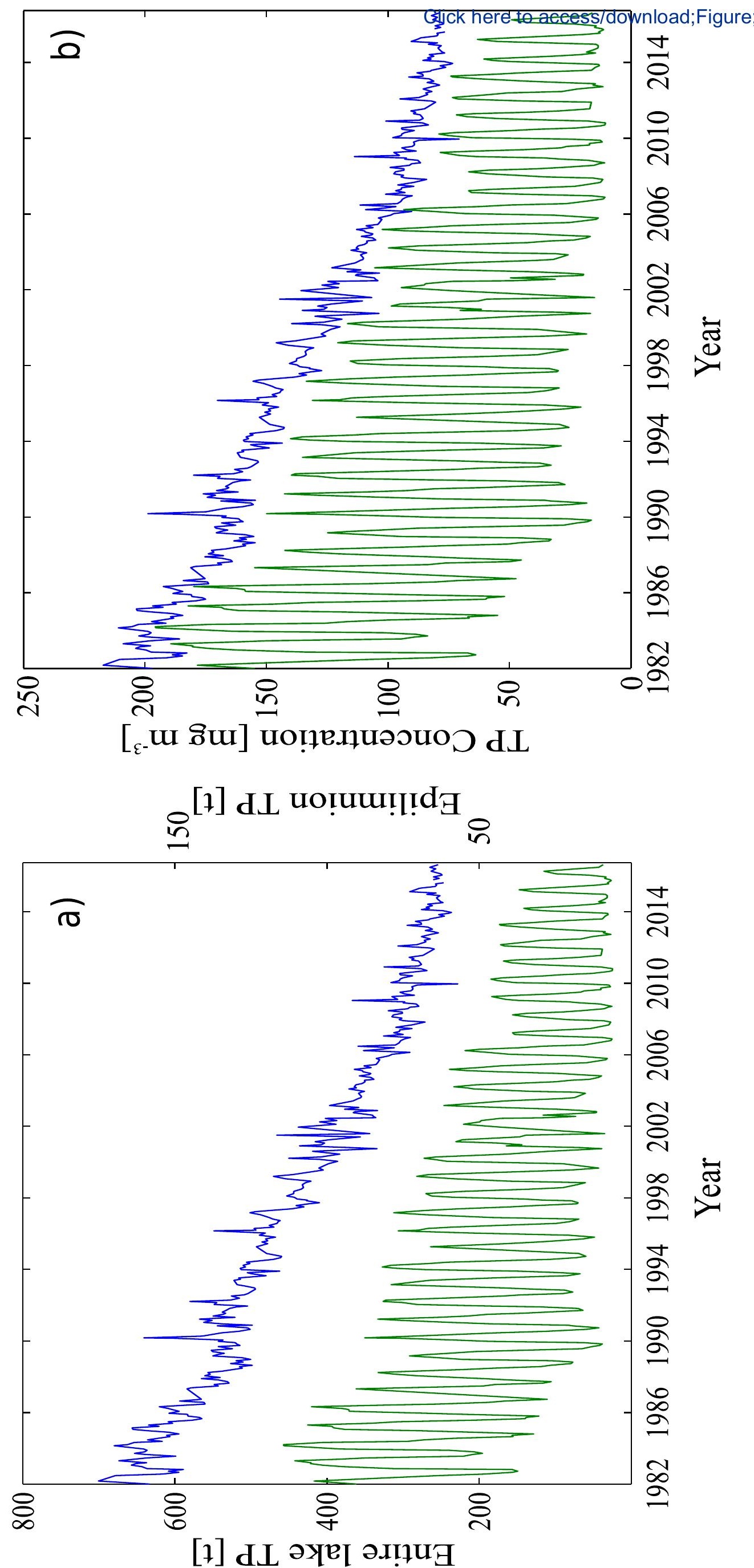

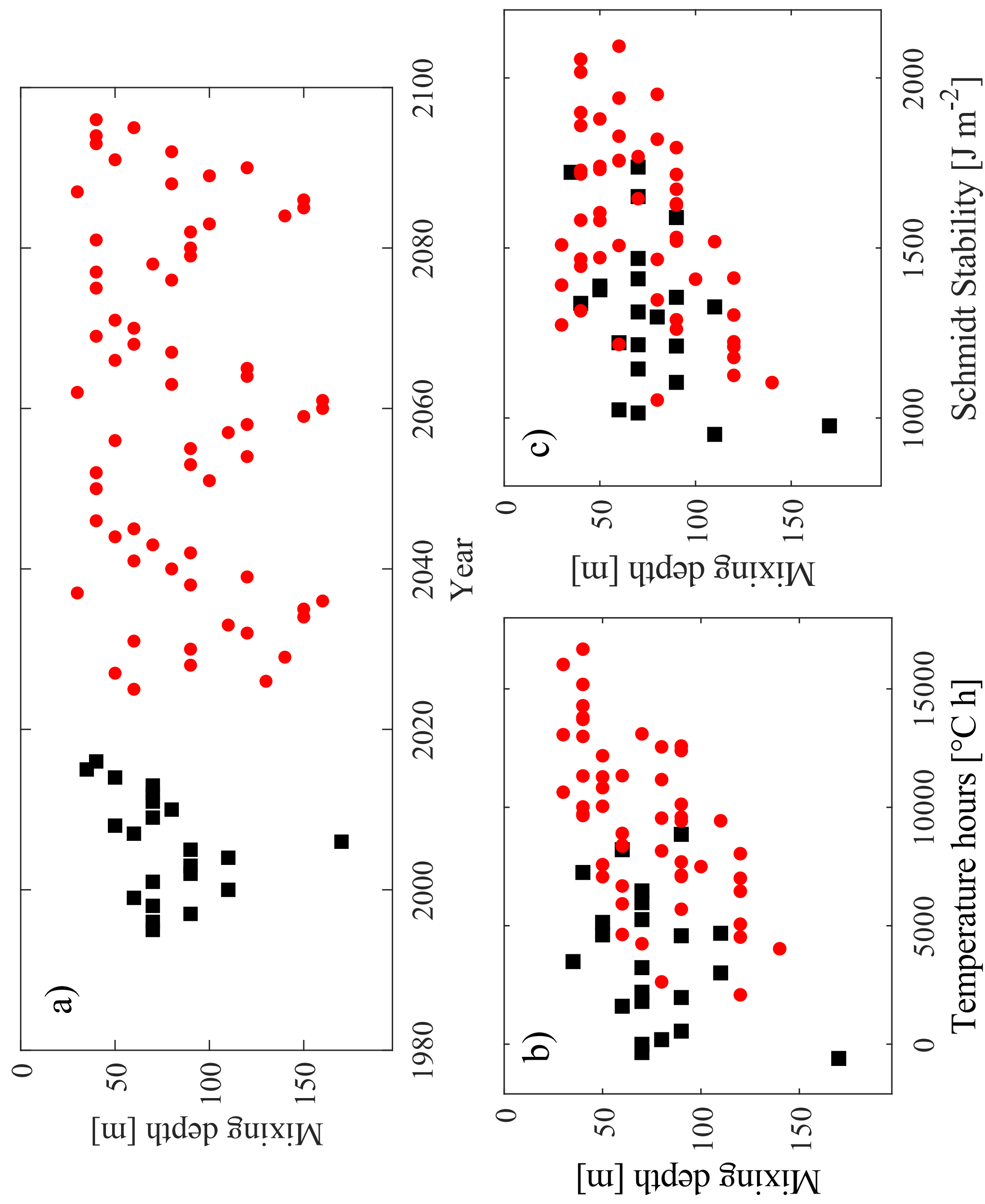


\title{
Global warming affects nutrient upwelling in deep lakes \\ Supporting Information
}

\author{
Robert Schwefel $^{1 *}$, Beat Müller ${ }^{2}$, Hélène Boisgontier ${ }^{1}$, and Alfred Wüest ${ }^{1,2}$ \\ ${ }^{1}$ Physics of Aquatic Systems Laboratory, Margaretha Kamprad Chair, École Polytechnique \\ Fédérale de Lausanne, Institute of Environmental Engineering, Lausanne, Switzerland. \\ ${ }^{2}$ Eawag, Swiss Federal Institute of Aquatic Science and Technology, Surface Waters - Research \\ and Management, Kastanienbaum, Switzerland.
}

\section{Content}

Table S1: Seasonal changes in future air temperatures according to IPCC emission scenarios.

Figure S1: Histogram of wind speed at Lake Zug.

Figure S2: Concentrations of total phosphorus, total dissolved phosphorus and dissolved inorganic phosphorus end of winter and in summer.

Figure S3: Euphotic zone depth of Lake Zug.

Figure S4: Monin-Obukhov length for Lake Zug. 
Table S1: Seasonal changes in air temperatures according to different IPCC emission scenarios for the years 2035, 2060 and 2085. The predictions were taken from the climate report $\mathrm{CH} 2011$.

\begin{tabular}{|c|c|c|c|c|c|}
\hline Scenario & $\begin{array}{c}\Delta \mathrm{T} \\
\text { March - May }\end{array}$ & $\begin{array}{c}\Delta \mathrm{T} \\
\text { June }- \text { August }\end{array}$ & $\begin{array}{c}\Delta \mathrm{T} \\
\text { Sept. }- \text { Nov. }\end{array}$ & $\begin{array}{c}\Delta \mathrm{T} \\
\text { Dec. }- \text { Feb. }\end{array}$ & $\begin{array}{c}\Delta \mathrm{T} \\
\text { average }\end{array}$ \\
\hline A2 2035 & +0.83 & +1.15 & +1.12 & +1.13 & +1.06 \\
\hline A2 2060 & +1.95 & +2.54 & +2.14 & +2.26 & +2.22 \\
\hline A2 2085 & +3.27 & +4.36 & +3.69 & +3.64 & +3.74 \\
\hline A1B 2035 & +0.94 & +1.28 & +1.25 & +1.26 & +1.18 \\
\hline A1B 2060 & +1.99 & +2.59 & +2.18 & +2.31 & +2.27 \\
\hline A1B 2085 & +2.77 & +3.74 & +3.16 & +3.12 & +3.20 \\
\hline RCP3PD 2035 & +0.89 & +1.21 & +1.19 & +1.26 & +1.14 \\
\hline RCP3PD 2060 & +1.19 & +1.55 & +1.30 & +1.38 & +1.33 \\
\hline RCP3PD 2085 & +1.18 & +1.59 & +1.35 & +1.33 & +1.36 \\
\hline
\end{tabular}

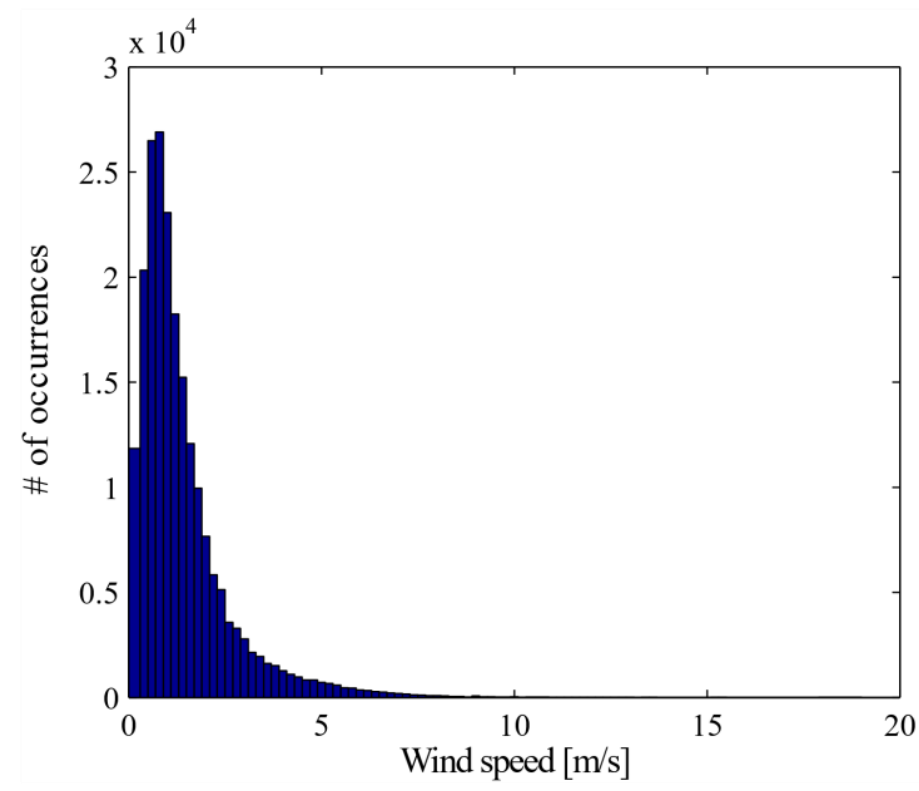

Figure S1: Histogram of hourly measured wind speed at the meteorological station Cham (Fig. 1d) between June 1993 and July 2017 (in total 43,340 measurement points). In 78\% of the measurements, wind speed is lower than $2 \mathrm{~m} \mathrm{~s}^{-1}$. 


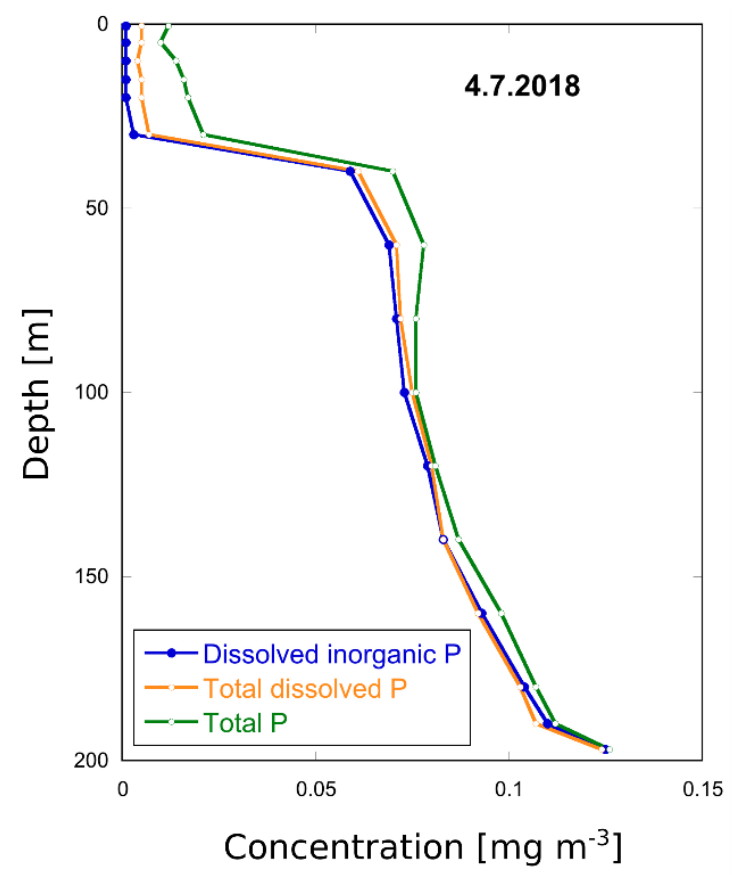

Figure S2: Concentrations of dissolved inorganic phosphorus, total dissolved phosphorus and total phosphorus after convective winter mixing (left) and in summer (right).

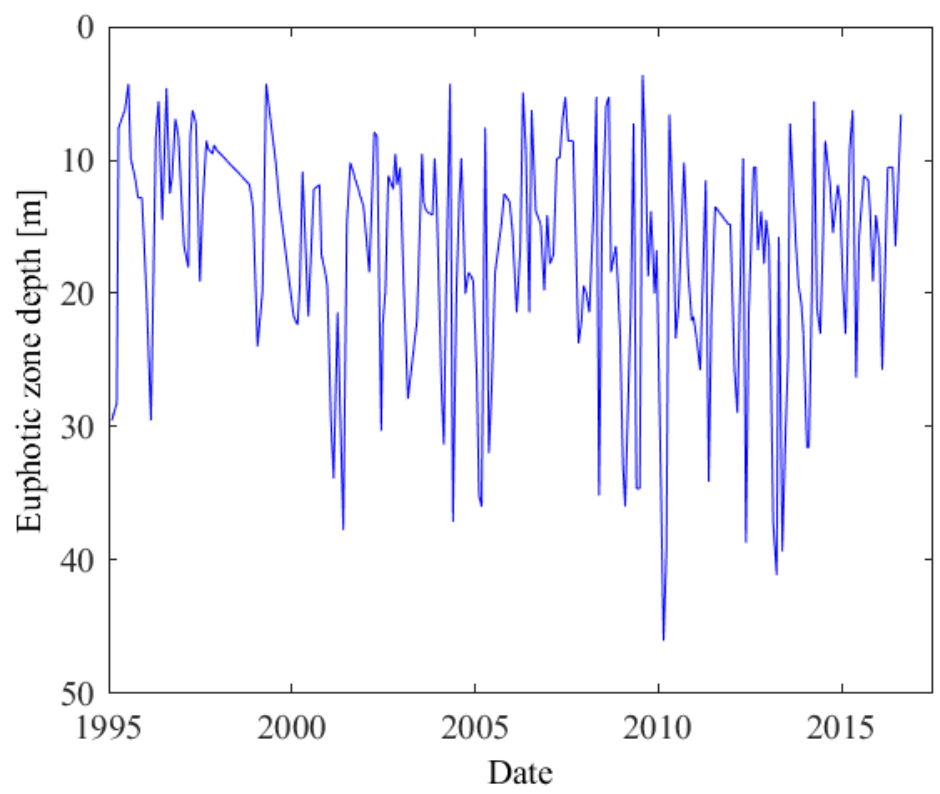

Figure S1: Euphotic zone depth of Lake Zug defined as depth where $99 \%$ of the light is absorbed. Absorption coefficients were calculated based on Secchi depth according to Fink et al. (2014b) and were also used for the 1D model SIMSTRAT. 


\section{References}

Fink G, Schmid M, Wahl B, Wolf T, Wüest A (2014a) Heat flux modifications related to climateinduced warming of large European lakes. Water Resour Res 50:2072-2085. doi: 10.1002/2013WR014448

Fink G, Schmid M, Wüest A (2014b) Large lakes as sources and sinks of anthropogenic heat: Capacities and limits. Water Resour Res 50:7285-7301. doi: 10.1002/2014WR015509

Figure S4: Monin-Obukhov length calculated for the years 2000 to 2003. Monin-Obukhov length was calculated as $L_{M O}=$ $-\left(\frac{\rho_{\text {air }} C_{10}}{\rho_{\text {water }}}\right)^{3 / 2} \frac{u_{10}^{3}}{k J_{B}}$. The air (water) density is denoted as $\rho_{\text {air }}\left(\rho_{\text {water }}\right)$, the drag coefficient as $C_{10}$, the van Kármán constant $k$ $(=0.41)$ and $J_{B}=\frac{\alpha g}{\rho_{\text {water }} c_{p}} H_{n e t}$ with the gravity acceleration constant $g$, the thermal expansivity $\alpha$ and the specific heat $\rho_{\text {water }} c_{p}$. The heat flux was calculated according to Fink et al. (2014a). Values were calculated based on observational data as daily averages. Surface temperature was not available on a daily basis and had to be interpolated from monthly lake measurements. Hence, some of the larger outlier might have been caused by too sparse surface temperature data. 